\title{
Cellular detection of the chemokine receptor CXCR4 in bovine mammary glands and its distribution and regulation on bovine leukocytes
}

\author{
Denis Revskij, ${ }^{1}$ ○ Susanne Haubold, ${ }^{1} \oplus$ Christian Plinski, ${ }^{1}$ () Torsten Viergutz, ${ }^{1}$ Armin Tuchscherer, ${ }^{1}$ \\ Claudia Kröger-Koch, ${ }^{1}$ Elke Albrecht, ${ }^{1} \odot$ Juliane Günther, ${ }^{1} \odot$ Arnulf Tröscher, ${ }^{2} \odot$ Harald M. Hammon, ${ }^{1} \odot$

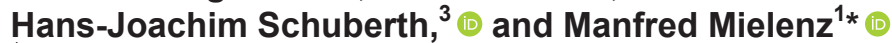 \\ ${ }^{1}$ Research Institute for Farm Animal Biology (FBN), 18196 Dummerstorf, Germany \\ ${ }^{2}$ BASF SE, Chemiestraße 22, 68623 Lampertheim, Germany \\ ${ }^{3}$ Institute of Immunology, University of Veterinary Medicine, Foundation, Buenteweg 2, 30559 Hannover, Germany
}

\begin{abstract}
Mastitis has a high incidence in dairy cows. Experimental infection with Escherichia coli increased the number of leukocytes in milk and the gene expression of the chemokine receptor CXCR4 in mammary gland tissues. A link between CXCR4 expression and lipopolysaccharide sensing was demonstrated in other species using in vitro models. The receptor that binds the chemokine stomal cell-derived factor 1 might be associated with the inflammatory response in bovine mammary glands. However, studies in cows are rare, and data on the localization of CXCR4 in bovine mammary glands and its distribution in bovine leukocytes are lacking. Fatty acids (FA) affect the inflammatory response. In human peripheral blood monocytes, exposure to conjugated linoleic acids (CLA) decreases the expression of CXCR4, leading to a decreased inflammatory response in these cells. In this study, we analyzed the expression of CXCR4 in the mammary glands of dairy cows by immunohistochemistry $(\mathrm{n}=5)$ and laser capture microdissection followed by qualitative PCR $(\mathrm{n}=3)$. We characterized the surface expression of CXCR4 on bovine leukocytes, including monocyte subpopulations, first by flow cytometry $(\mathrm{n}=5)$ and then confirmed these results by Western blotting $(\mathrm{n}=3)$. Rumen fistulated dairy cows ( $\mathrm{n}=4 ; 126 \pm 4 \mathrm{~d}$ in milk) were fitted with abomasal infusion tubes, arranged in a $4 \times 4$ Latin square design, and supplemented for 6 wh twice daily with rising doses of FA followed by a 3 -wk washout period. Then, CXCR4 expression on leukocytes was analyzed. The cows received a corn-based diet and were supplemented with coconut oil delivering medium-chain FA (38 g/d), linseed-safflower oil mix delivering n-3 FA (EFA, $39 \mathrm{~g}$ of linseed oil and $2 \mathrm{~g}$ of
\end{abstract}

Received May 28, 2021.

Accepted September 17, 2021.

*Corresponding author: mielenz@fbn-dummerstorf.de safflower oil per day), Lutalin (cis-9,trans-11 and trans10,cis-12 CLA, $5 \mathrm{~g} / \mathrm{d}$; BASF), and EFA + CLA. In the bovine mammary gland, the epithelial cells of the lactiferous duct, but not alveolar epithelial cells, showed clear CXCR4 protein and mRNA signals. Among the leukocyte subsets, monocytes displayed the highest percentage of CXCR4-positive cells (87\%), whereas circulating neutrophils showed almost no CXCR4 surface expression (3\%) but stored the receptor intracellularly. The percentage of CXCR4-positive leukocytes was not affected by the different FA supplements, but FA supplementation reduced the receptor abundance per cell (40\% on average). In conclusion, CXCR4 was clearly detected in the lactiferous duct cells of the mammary gland but not in the alveolar epithelial cells. Compared with other leukocytes, bovine monocytes showed the highest signal intensity of CXCR4 on their surface, whereas granulocytes stored CXCR4 intracellularly. Supplementation with all the FA reduced the surface expression of CXCR4 per leukocyte and could therefore potentially affect the inflammatory status associated with the surface expression of CXCR4. The importance of our observations should be verified in cows with mastitis in the future.

Key words: dairy cow, CXCR4, leukocyte, essential fatty acids, mammary gland

\section{INTRODUCTION}

Mastitis is an economically relevant disease with a high incidence in dairy cows. Mastitis is the main reason for administering antimicrobial therapy to this species (Jamali et al., 2018). Experimental infection of the bovine mammary gland with Escherichia coli increased the number of leukocytes in the milk and the gene expression of the chemokine receptor $\mathrm{CXCR}_{4}$ in the mammary gland tissues (Mitterhuemer et al., 2010). In addition, there is some evidence from in vitro experiments using human monocyte, hybridoma, or Chinese 
hamster ovary cell models that the CXCR4 receptor binds bacterial LPS, forming clusters with other LPS receptors, such as toll-like receptor 4 , and is part of the LPS-sensing apparatus (Triantafilou et al., 2001; Triantafilou et al., 2008). The receptor might therefore be involved in mechanisms related to the acute inflammatory response within the mammary gland. However, data on the precise location of cells expressing CXCR4 in bovine udders are still limited. Interestingly, in addition to inflammatory stimuli, hormones such as progesterone can affect the expression of CXCR4, as demonstrated in mouse mammary glands. In this species, the expression of CXCR4 increases during pregnancy, and CXR4 is involved in the functional differentiation of alveoli in the adult mammary gland (Shiah et al., 2015). Bovine chemokine receptors such as CXR4 were first characterized by Widdison et al. (2010), but studies on the function of CXCR4 in cows are rare (Mitterhuemer et al., 2010; Weiner et al., 2012; Sayasith and Sirois, 2014), and concrete data on the expression of the receptor on bovine leukocytes are missing.

Chemokines are a subfamily of cytokines that are involved in cell migration, cell differentiation, and cell growth (Altenburg and Siddiqui, 2009). One of the most well-studied chemokine receptors is CXCR4 (CD184) mainly because of its role as a coreceptor for HIV-1 entry into $T$ cells and its involvement in the metastasis of a variety of cancers (Busillo and Benovic, 2007). This chemokine receptor is widely expressed on hematopoietic cells, neuronal cells, endothelial cells, and epithelial cells (Teicher and Fricker, 2010). The CXCR4 selectively binds the CXC chemokine stromal cell-derived factor 1, also known as CXCL12 (Döring et al., 2014).

The receptor CXCR4 is involved in numerous processes, including cell migration, cell adhesion, and leukocyte extravasation (Nie et al., 2004; Altenburg and Siddiqui, 2009). This receptor regulates T cell maturation (Bleul et al., 1997), maintains neutrophil homeostasis (Eash et al., 2009), and mediates neutrophil (Eash et al., 2009) and monocyte (de Gaetano et al., 2013) recruitment to sites of inflammation. Inflammatory cytokines are known to modulate the expression of CXCR4 in different cell types and show a biphasic effect on CXCR4 expression, with early downregulation and later upregulation (Brühl et al., 2003; Salcedo and Oppenheim, 2003).

Conjugated linoleic acids, positional isomers of linoleic acid (LA), decrease the expression of CXCR4 and integrin $\beta-2$ in human peripheral blood monocytes, leading to a decreased inflammatory response (de Gaetano et al., 2013). The CLA are found predominantly in ruminants as intermediate products of the biohydrogenation of UFA, such as the n-3 fatty acid (FA) $\alpha$-linolenic acid (ALA) and the n-6 FA LA (Bauman et al., 2000). Fatty acids, especially essential n-3 and n-6 FA (EFA), such as ALA and LA, are important components of the plasma membrane. Furthermore, EFA and its derivatives serve as precursors of several signaling molecules, including prostaglandins and leukotrienes (Simopoulos, 2008). Specifically, n-3 EFA has anti-inflammatory potential (Das, 2008).

In high-yielding dairy cows, corn silage is an important component of common diets (Phipps et al., 1995; Khan et al., 2015) that provides enough energy to meet the high demand for milk production. Compared with grass-based silage or pasture, corn silage delivers high amounts of LA but low amounts of ALA (Rego et al., 2004; Hart et al., 2015; Haubold et al., 2020). This composition is associated with a higher n-6/n-3 FA ratio (Haubold et al., 2020), which is associated with a higher incidence of metabolic diseases and inflammation, as demonstrated in humans (Zárate et al., 2017; Harris, 2018). Currently, the minimal requirement for n-3 EFA in dairy cows is unknown (Palmquist, 2010).

We first aimed to confirm and localize CXCR4 expression in mammary gland tissue by immunohistochemistry. We confirmed its mRNA expression at the cellular level by laser capture microdissection, followed by PCR. Then, we characterized the expression of CXCR4 on bovine circulating leukocytes. Second, we hypothesized that a diet low in n-3 FA affects the expression of CXCR4. We therefore evaluated the distribution of CXCR4 and the effects of supplementation with EFA or CLA on the protein expression of CXCR4 on leukocyte subpopulations in dairy cows fed a cornbased diet.

\section{MATERIALS AND METHODS}

All the procedures were conducted in agreement with the recommendations for the use of animals as experimental subjects of the State Government in Mecklenburg-West Pomerania (Registration No. LALLF M-V/ TSD/7227.3-1-061/14).

\section{Animals and Study Design}

Mammary gland tissue was obtained from the slaughterhouse of the Research Institute for Farm Animal Biology (FBN; Dummerstorf, Germany) and used for histological analyses. The tissue samples originated from healthy German Holstein cows $(>10,000 \mathrm{~kg}$ of milk in $305 \mathrm{~d}$ in second lactation) and were not part of the animal trial below. The tissues were frozen in liquid nitrogen and stored at $-80^{\circ} \mathrm{C}$. To analyze the effects 
of fatty acid supplementation on CXCR4 distribution on bovine leukocytes, German Holstein cows $(\mathrm{n}=4$; $>10,000 \mathrm{~kg}$ of milk in $305 \mathrm{~d}$ in second lactation; 126 $\mathrm{DIM} \pm 4$ at start of the study), which were part of a previously published study (Haubold et al., 2020), were fitted with an abomasal infusion tube via a rumen fistula and were housed in a freestall barn at the FBN. These cows were given access to water and food ad libitum. The animals received a corn silage-based TMR $\left(\mathrm{NE}_{\mathrm{L}:} 6.7 \mathrm{MJ} / \mathrm{kg}\right.$ of $\mathrm{DM} ; \mathrm{CP}$ and fat content: 149 and $24.4 \mathrm{~g} / \mathrm{kg}$ of DM, respectively) delivering lower amounts of n-3 FA (Haubold et al., 2020) starting 3 mo before the initiation of the trial. This ration was in accordance with the German Society of Nutrition Physiology (GfE, 2001, 2008).

Using a Latin square design, the cows were supplemented with 4 different FA. In the course of the experiment, the initial dosage of each FA supplement was doubled every 2 wk, resulting in a 6-wk supplementation period of each FA supplement, followed by a 3-wk washout period (WO). Then, the supplement was changed (for details on the supplementation scheme, see Revskij et al., 2019). The FA supplements were (1) coconut oil (control), delivering 93\% SFA (38.3 g/d; Sanct Bernhard); (2) a mix of linseed (39.1 g/d; DERBY, Derby Spezialfutter) and safflower oil $(1.6 \mathrm{~g} / \mathrm{d}$; GEFRO; EFA, delivering $52.3 \%$ n-3 FA and $17.4 \%$ n-6 FA, respectively, resulting in an n-6:n-3 FA ratio of 1:3); (3) Lutalin (BASF; CLA, $16 \mathrm{~g} / \mathrm{d}$, providing $4.6 \mathrm{~g} / \mathrm{d}$ of each cis-9,trans-11 and trans-10, cis-12 CLA isomer); and (4) the combination of EFA and CLA (EFA + CLA; $40.7 \mathrm{~g} / \mathrm{d}+16 \mathrm{~g} / \mathrm{d}$, respectively). The FA supplements were infused manually each day via an abomasal tube and divided into 2 equal servings after milking at 0700 and $1600 \mathrm{~h}$. Detailed data on the composition of the diet and FA supplements are listed in Supplemental Tables S1-S3 (https://doi.org/ 10.5281/zenodo.5243358; Revskij et al., 2021). Further information on the animal experiment and animal performance are available in the publications by Revskij et al. (2019) and Haubold et al. (2020). These data were extended with subexperiments (1) using samples from 3 pluriparous lactating dairy cows of the FBN that were randomly selected to first verify intracellular CXCR4 protein expression in leukocytes; (2) analyzing the distribution of CXCR4 on the monocyte subpopulations of 5 healthy pluriparous German Holstein cows of the FBN (>10,000 kg of milk in $305 \mathrm{~d}$ in second lactation); and (3) evaluating the effects of FA on monocytes and macrophages in vitro using blood samples of 2 randomly selected, nonlactating, healthy pluriparous cows of the University of Veterinary Medicine, Foundation (Hannover, Germany). The data from the subexperiments are shown partly as supplementary data.

\section{Immunohistochemical Detection of CXCR4 Expression in Mammary Gland Tissues}

Immunohistochemical analysis was performed as previously described (Aguinaga Casañas et al., 2017). Briefly, frozen mammary gland tissues from 5 cows were cryosectioned in 6- to 8 - $\mu \mathrm{m}$-thick sections using a Leica CM $3050 \mathrm{~S}$ cryostat microtome (Leica). The sections were air-dried and fixed for 20 min with $4 \%$ paraformaldehyde or for $10 \mathrm{~min}$ with ice-cold acetone and washed with PBS. To reduce autofluorescence, the sections were incubated for $30 \mathrm{~min}$ in a solution of $0.1 \%$ Sudan Black in $70 \%$ ethanol. Nonspecific binding of the secondary antibody (Ab) was blocked using 10\% normal goat serum in PBS for $15 \mathrm{~min}$. The sections were incubated with a primary rabbit antibovine CXCR4 Ab (Biozol, \#orb10305, 1:100 in PBS including 2\% normal goat serum) for $1 \mathrm{~h}$ at RT. After washing 3 times for 10 min, a secondary Ab (Alexa Fluor 488-labeled goat antirabbit Ab, 1:500, Fisher Scientific) was added and incubated for $45 \mathrm{~min}$ in the dark at room temperature (RT). The nuclei were counterstained with Hoechst $33258(1 \mu \mathrm{g} / \mathrm{mL}$, Sigma-Aldrich, \#14530). All the incubations were performed in a humid chamber. The sections were covered with ProLong Diamond Antifade Mountant (Fisher Scientific) and appropriate coverslips. Negative controls were generated by omitting the primary Ab. Immunofluorescence was visualized with a Nikon Microphot SA fluorescence microscope (Nikon) and an image analysis system equipped with a CC12 high resolution color camera and CELL^F software (OSIS, ver. 3.4, 2011).

\section{Laser Capture Microdissection and Detection of CXCR4 mRNA in Mammary Gland Tissue}

Alveolar epithelial cells (AV) and lactiferous duct epithelial cells (LD) were selected by laser capture microdissection according to procedures previously described by Albrecht et al. (2011) with slight modifications using 3 different animals. Briefly, mammary gland samples were cut into $10-\mu \mathrm{m}$ serial sections on a cryostat microtome (CM $3050 \mathrm{~S}$, Leica) at $-20{ }^{\circ} \mathrm{C}$. One slice was used as a control section and was placed directly in lysis buffer and frozen on dry ice. Several serial sections were simultaneously transferred to a PALM membrane slide (PALM) and air-dried. The sections were then successively placed in $70 \%$ ethanol $\left(-20^{\circ} \mathrm{C}\right)$, $96 \%$ ethanol and $2 \times$ absolute ethanol at room temperature and incubated for $30 \mathrm{~s}$ each. To complete the dehydration procedure, the sections were transferred to a container with xylene, gently washed by moving up and down, and placed in a second container with xylene for $5 \mathrm{~min}$. Finally, the sections were air-dried under a 
fume hood. The sections were immediately used for laser microdissection (MicroBeam, PALM). The regions for cutting alveoli and cells of the lactiferous duct were marked and cut. For each sample, at least 300 cells were collected in an adhesive cap (PALM) and lysed in buffer RLT (RNeasy Micro Kit, Qiagen). RNA extraction was performed according to the manufacturer's instructions. The extracted RNA was stored at $-80{ }^{\circ} \mathrm{C}$ until analysis.

The CXCR4 RNA expression was analyzed as described by Stoldt et al. (2016) with some modifications. Briefly, the extracted total RNA $(11 \mu \mathrm{L})$ was completely reverse transcribed together with leukocyte total RNA as a positive $C X C R 4$ control using random hexamer primers (250 pmol; Metabion International) and RevertAid reverse transcriptase (400 U; Thermo Fisher Scientific) with dNTP Mix $(10 \mu M$ each; Thermo Fisher Scientific) in a total volume of $40 \mu \mathrm{L}$ using a thermocycler (Biometra). A no reverse transcriptase control and a cDNA-negative template control were included in each run. The sample cDNAs were tested undiluted and diluted 1:4. Each PCR run consisted of no reverse transcriptase control of cDNA, cDNA negative template control, and negative template control for PCR. All the samples were prepared as duplicates. For PCR, $2 \mu \mathrm{L}$ cDNA as template and $10 \mu \mathrm{L}$ SensiFast SYBR NO-ROX Kit Mix (Bioline) were mixed in white 96-well plates (LightCycler 96 Multiwell Plate 96, Roche Diagnostics) and run in a LightCycler 96 system (Roche Diagnostics). The primer characteristics and real-time PCR conditions are listed in Supplemental Table S4 (https://doi.org/10.5281/zenodo.5243358, Revskij et al., 2021). The resulting PCR products were verified by agarose gel electrophoresis and sequencing using the BigDye Terminator v1.1 Cycle Sequencing kit and an ABI 3130 Genetic Analyzer (Life Technologies).

\section{Isolation of Peripheral Blood Mononuclear Cells and Stimulation with Phorbol 12-myristate 13-acetate}

Bovine peripheral blood mononuclear cells (PBMC) were isolated from whole blood by density gradient centrifugation using Biocoll (Biochrom). Heparinized blood was diluted 1:2 with cold $\left(4^{\circ} \mathrm{C}\right)$ PBS (PAN Biotech) and carefully layered over Biocoll, followed by centrifugation $(1,210 \times g, 20 \mathrm{~min}, \mathrm{RT})$. Then, the PBMC were pooled and washed $(300 \times g, 10 \mathrm{~min}$, $\left.4^{\circ} \mathrm{C}\right)$ with cold $\left(4^{\circ} \mathrm{C}\right) \mathrm{PBS}$, and the supernatant was discarded. To remove erythrocyte contamination, the cells were resuspended in $20 \mathrm{~mL}$ of cold $\left(4^{\circ} \mathrm{C}\right)$ ultrapure water. After $15 \mathrm{~s}$, hypotonic lysis was stopped by adding $2 \times \mathrm{PBS}\left(4^{\circ} \mathrm{C}\right)$ in equal amounts. Subsequently, the cells were washed $\left(300 \times \mathrm{g}, 10 \mathrm{~min}, 4^{\circ} \mathrm{C}\right)$. After washing, the supernatant was removed, and the cell pellet was resuspended in $20 \mathrm{~mL}$ of RPMI-1640 medium containing $100 \mathrm{U}$ of penicillin/mL, $100 \mathrm{mg} / \mathrm{mL}$ streptomycin (PAN Biotech), $2 \mathrm{~m} M$ L-glutamine (PAN Biotech), and $10 \%$ fetal calf serum (PAN Biotech; PBMC medium $)$ and washed $\left(300 \times g, 10 \mathrm{~min}, 4^{\circ} \mathrm{C}\right)$. Finally, the cells were resuspended in $1 \mathrm{~mL}$ of PBMC medium. Cell count and viability were estimated by using a Neubauer improved counting chamber (Brand) and Trypan Blue staining (Invitrogen). To analyze the effects of stimulating proliferation on CXCR4 surface expression, $3 \times 10^{5}$ washed and isolated cells were treated with the mitogen phorbol 12-myristate 13-acetate (PMA; InvivoGen) at a final concentration of 2 $\mu M$. The cells were incubated for $1 \mathrm{~h}$ at $37^{\circ} \mathrm{C}$ and $5 \%$ $\mathrm{CO}_{2}$ and stored on ice until analysis.

\section{Flow Cytometric Determination of the Proportion of CXCR4-positive Cells among Bovine Leukocytes}

Determination of CXCR4 surface abundance on total leukocytes and isolated PBMC was performed by flow cytometric analysis, according to procedures previously described by Viergutz et al. (2000) with slight modifications. Briefly, to isolate total leukocytes, EDTA-treated blood $(100 \mu \mathrm{L})$ was incubated $(20 \mathrm{~min}, \mathrm{RT})$ with $1 \mathrm{~mL}$ VersaLyse lysing solution (Beckman Coulter), washed $(300 \times g, 5 \mathrm{~min}$ at $\mathrm{RT})$ and resuspended in $1 \mathrm{~mL}$ of PBS. After a second washing step, the cell pellet was resuspended in $200 \mu \mathrm{L}$ of PBS containing $2 \mathrm{~m} M$ EDTA and $0.5 \%$ BSA. Finally, the cells were washed in $1 \mathrm{~mL}$ of PBS, and the cell pellet was resuspended in $500 \mu \mathrm{L}$ of PBS.

Total leukocytes or isolated $\mathrm{PBMC}$ were fixed in methanol $\left(100 \%,-20^{\circ} \mathrm{C}, 10 \mathrm{~min}\right)$ using one volume of cell suspension and 10 volumes of methanol. The cells were washed $\left(150 \times \mathrm{g}, 4^{\circ} \mathrm{C}, 5 \mathrm{~min}\right)$ and resuspended in PBS containing $0.5 \%$ (wt/vol) BSA and $2 \mathrm{~m} M$ EDTA $\left(\mathrm{pH}\right.$ 7.4). The cells were incubated overnight $\left(4^{\circ} \mathrm{C}\right)$ with a rabbit anti-CXCR4 Ab (Biozol) at a final concentration of $5 \mu \mathrm{g} / \mathrm{mL}$. Unbound Abs were removed by washing, and the cells were resuspended in PBS. Then, the cells were incubated for $1 \mathrm{~h}$ at RT with $2 \mu \mathrm{g} / \mathrm{mL}$ goat antirabbit Alexa Fluor 488-conjugated F(ab') $\mathrm{Ab}$ fragments (Thermo Fisher Scientific, \#A11034) in PBS [pH 7.2, 0.5\% (wt/vol); BSA, $2 \mathrm{mM}$ EDTA]. After washing and resuspension in PBS, the portion of CXCR4-positive cells was quantified by flow cytometric analysis using a $488 \mathrm{~nm}$ argon laser equipped flow cytometer (Gallios, Beckman Coulter). The cells of interest (lymphocytes, monocytes, and granulocytes) were identified by their size and granularity. The percentage of CXCR4-positive cells and the mean fluorescence intensity per cell were automatically computed. The analysis was performed with Kaluza software, ver- 
sion 1.2 (Beckman Coulter). Independent of the above study, we characterized the expression of CXCR4 on different monocyte subsets and leukocytes stimulated with fatty acids ex vivo using different instrumentation (Supplemental Table S5, Supplemental Figures S1 and S2; https://doi.org/10.5281/zenodo.5243358, Revskij et al., 2021).

\section{Immunoprecipitation of CXCR4}

Immunoprecipitation analyses were performed as previously described (Richter et al., 2015). Briefly, approximately $3 \times 10^{5}$ isolated and sorted leukocytes from 3 healthy cows were washed 3 times with PBS and lysed with $100 \mu \mathrm{L}$ of RIPA buffer containing protease inhibitor cocktail (Sigma-Aldrich; the sorting protocol and the results of cell sorting by flow cytometry are provided as Supplemental Materials and Methods and Supplemental Figure S1, https://doi.org/10.5281/ zenodo.5243358, Revskij et al., 2021). Proteins were extracted by sonication of the cells using an ultrasonic homogenizer (Labsonic-M, Sartorius) and centrifuged at $14,000 \times g$ for $10 \mathrm{~min}$ at $4^{\circ} \mathrm{C}$. The supernatant was precleaned on protein $\mathrm{A} / \mathrm{G}$ columns (Pierce Classic IP Kit, Thermo Fisher Scientific), diluted 1:2 with binding buffer and treated with the anti-CXCR4 Ab from Biozol $(2 \mu \mathrm{g} / \mathrm{mL}$ for cell lysate, 2 to $10 \mu \mathrm{g} / \mathrm{mL}$ for plasma). Protein concentrations were determined using the Bradford method according to standard protocols. Equal amounts of proteins $(30 \mu \mathrm{g} / \mathrm{lane})$ were loaded and separated by SDS-PAGE. Western blotting analysis was performed using rabbit anti-CXCR4 Ab (Abcam, \#E18440) at a final concentration of $5 \mu \mathrm{g} / \mathrm{mL}$. Signal detection was performed via the ECL system using standard protocols and the Gel Doc EZ system using Image Lab software 6.0.0 build 25 for image analysis (both from Bio-Rad).

\section{Statistical Analysis}

Statistical analyses were performed using SAS software for Windows, version 9.4 (SAS Institute Inc.). Descriptive statistics and tests for normality were conducted with the UNIVARIATE procedure of the Base SAS software. The data collected after supplementation with the highest dosage (dosage III, wk 6) and after a 3 -wk WO were evaluated by repeated measurement ANOVA using the MIXED procedure in SAS/STAT software. The ANOVA model contained the fixed factors treatment (control, EFA, CLA, and EFA+CLA), dosage (WO and dosage III) and the interaction of treatment $\times$ dosage. Weeks in milk (time) served as covariate. Repeated measures were taken into account by using the REPEATED statement of the MIXED procedure (repeated variables: treatment, dosage) and a compound symmetry type of the block diagonal residual covariance matrix. Least squares means (LSM) and their standard errors (SE) were computed for each fixed effect in the model, and all pairwise differences between LSM were tested using the Tukey-Kramer test. The results are presented as LSM \pm SE. Effects and differences were defined as significant with $P$ values $<0.05$.

\section{RESULTS}

\section{Detection of CXCR4 Protein and mRNA in Mammary Glands}

We aimed to analyze the distribution of the CXCR4 protein in mammary glands by immunohistochemistry and confirmed its expression by qualitative PCR after laser capture microdissection. Figure 1 shows mammary gland tissue sections immunostained for CXCR4 and counterstained with Hoechst 33258. The CXCR4 protein was detected in the epithelial cells of the LD, and on a small scale, we observed a signal within the $\mathrm{AV}$.

To confirm our observations, we analyzed CXCR 4 mRNA expression in LD and AV. The cells were collected by laser capture microdissection. Supplemental Figure S4 (https://doi.org/10.5281/zenodo.5243358, Revskij et al., 2021) shows a mammary gland section with LD marked for laser capture microdissection (Supplemental Figure S1A) and the dissected cells in the collection cap (Supplemental Figure S1B). After RNA isolation from laser capture microdissected cells, CXCR 4 mRNA was analyzed by qualitative PCR. This analysis confirmed distinct $C X C R 4$ gene expression in the bovine mammary gland. The epithelial cells of the lactiferous duct showed a clear CXCR 4 mRNA signal. The latter result was comparable to that of leukocyte mRNA, which was used as a positive control. No expression was detectable in $\mathrm{AV}$, as demonstrated by gel electrophoresis (Supplemental Figure S5; https://doi .org/10.5281/zenodo.5243358, Revskij et al., 2021).

\section{Distribution of CXCR4 on Leukocyte Subsets}

We analyzed the distribution of CXCR4 on total leukocytes by flow cytometric analysis. In detail, total leukocytes were isolated and gated according to their forward and side scatter properties (Figure $2 \mathrm{~A}-\mathrm{D}$ ). The portions of CXCR4-positive cells among the gated cells are shown in Figure $2(\mathrm{E}-\mathrm{G})$. The cells with the highest amount of CXCR4 protein per cell were the monocytes $(86.86 \%$, Figure 2F), followed by the lymphocytes (61.21\%, Figure 2E), whereas the surface expression of 
CXCR4 on granulocytes was slightly above the background $(2.86 \%$, Figure $2 \mathrm{G})$. In a further experiment, the monocyte fraction was sorted according to their subpopulations (Supplemental Figure S1; https://doi .org/10.5281/zenodo.5243358, Revskij et al., 2021).

Using immunoprecipitation, the CXCR4 protein was detected in comparable amounts in all the analyzed cell types, and no CXCR4 protein was observed in the flowthrough fraction (Figure 3).

\section{Effect of Fatty Acid Supplementation on CXCR4 Abundance on Total Leukocytes and Isolated Peripheral Blood Mononuclear Cells}

The results of the flow cytometric quantification of CXCR4 surface expression on isolated PBMC and total leukocytes are shown in Figure 4 (A,B) and Figure 5 (A,B), respectively. In vitro stimulation with the mitogen PMA showed no effects on the expression of CXCR4 on isolated PBMC (Figure 4). Furthermore, the supplementation of cows with different FA supplements in vivo revealed no effects on the portion of CXCR4- positive cells (Figure 4A) or the relative abundance per cell (Figure 4B), as measured in PBMCs.

The total leukocytes of cows treated with different oil supplements also showed no changes in the portion of CXCR4-positive cells (Figure 5A). In contrast, the relative abundance per cell decreased after FA supplementation compared with WO $(P<0.05$; Figure 5B). The data on the in vitro stimulation of leukocytes with fatty acids are provided in Supplemental Figure S2 and Supplemental Table S5 (https://doi.org/10.5281/ zenodo.5243358, Revskij et al., 2021).

\section{DISCUSSION}

In the present study, we verified the expression of CXCR4 in bovine mammary gland tissues. We characterized the expression of CXCR4 on bovine leukocyte subpopulations and analyzed the effects of the abomasal infusion of FA in dairy cows fed a corn-based TMR.

Our analyses of CXCR4 at the protein and mRNA levels in mammary gland LD and AV revealed a clear CXCR4 expression signal in LD cells, whereas CXCR4
CXCR4

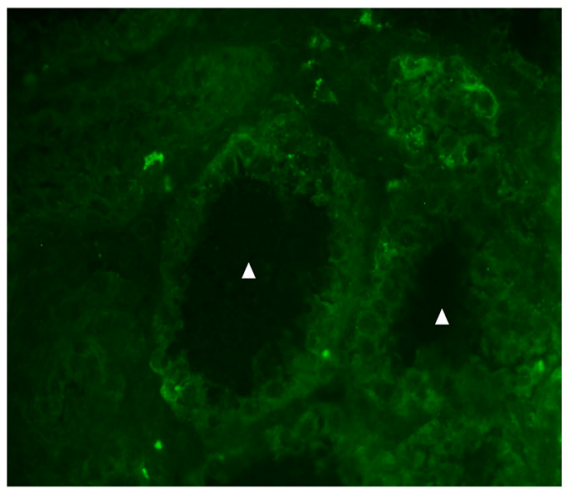

AV

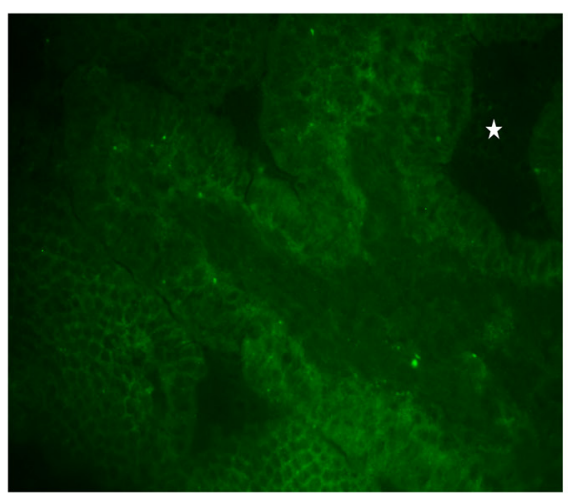

Hoechst 33258
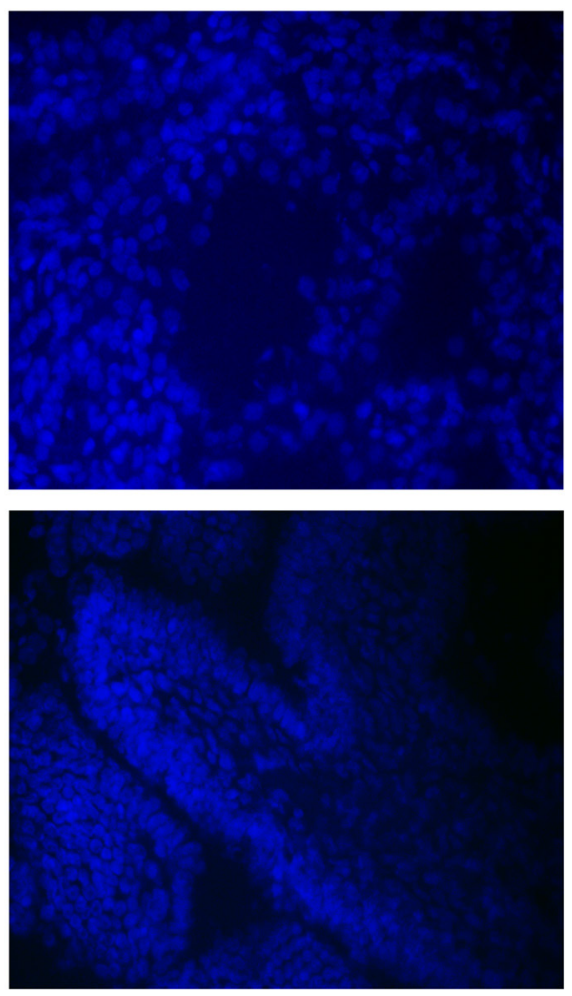

Merge
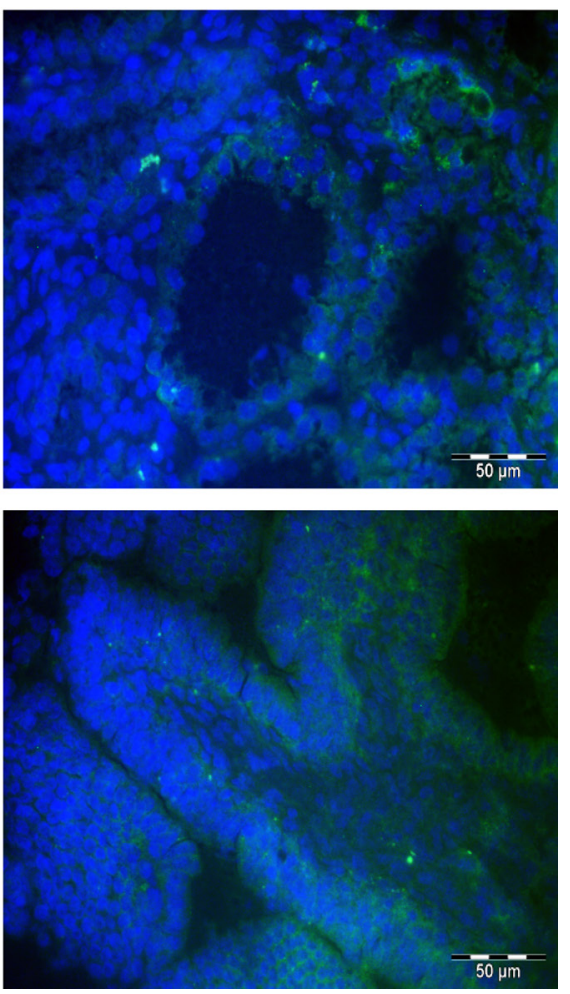

Figure 1. Fluorescence images of bovine mammary gland tissue cross sections immunostained for CXCR4. Shown is the presence of CXCR4 (green) in the cell membrane of the lactiferous duct (LD) and a low signal in the mammary gland alveoli (AV) of dairy cows sampled after slaughter. The nuclei were counterstained with Hoechst 33258 (blue). The CXCR4 fluorescence images were merged with Hoechst 33258 nuclear stain fluorescence images (Merge). The white triangles indicate mammary alveoli; the white star indicates lactiferous duct; $\mathrm{n}=5$ dairy cows. 
was only present at low levels or not detectable in $\mathrm{AV}$ according to our results. These results are comparable to data from the NCBI repository Gene Expression Omnibus (GEO, https://www.ncbi.nlm.nih.gov/geo/; Edgar et al., 2002). Two GEO data sets were generated from primary mammary epithelial cells and showed no or only minimal CXCR4 gene expression (GDS4437 and GDS4406). Furthermore, we cannot exclude the possibility that in addition to interstitial leukocytes, CXCR4-expressing dendritic cells in the bovine mammary gland (Widdison et al., 2010; Maxymiv et al., 2012) also produce some signal. However, the specific signals within the parenchymal tissue were low in our samples. In addition, there is some evidence that the CXCR4 receptor binds LPS and is part of the LPS sensing apparatus (Triantafilou et al., 2001; Triantafilou et al., 2008). As shown by Mitterhuemer et al. (2010),
E. coli infection leads to the upregulated expression of various cytokine receptor genes, including CXCR4 receptor mRNA, in total mammary gland tissue. However, data from 2 bovine GEO data sets, GDS4437 and GDS4406 (NCBI repository GEO, Edgar et al., 2002), using primary mammary gland epithelial cells stimulated with inactivated E. coli and Staphylococcus aureus cells showed no clear response of $C X C R 4$ expression.

It is not possible to exclude the possibility that activated resident immune cells or infiltrating leukocytes are responsible for the pattern of CXCR4 expression in $\mathrm{AV}$ and $\mathrm{LD}$ cells. We therefore aimed to improve our knowledge on the distribution and regulation of CXCR4 on leukocytes.

We analyzed the distribution of CXCR4 on distinct circulating leukocytes by flow cytometric analysis. Here, we clearly showed the surface expression of
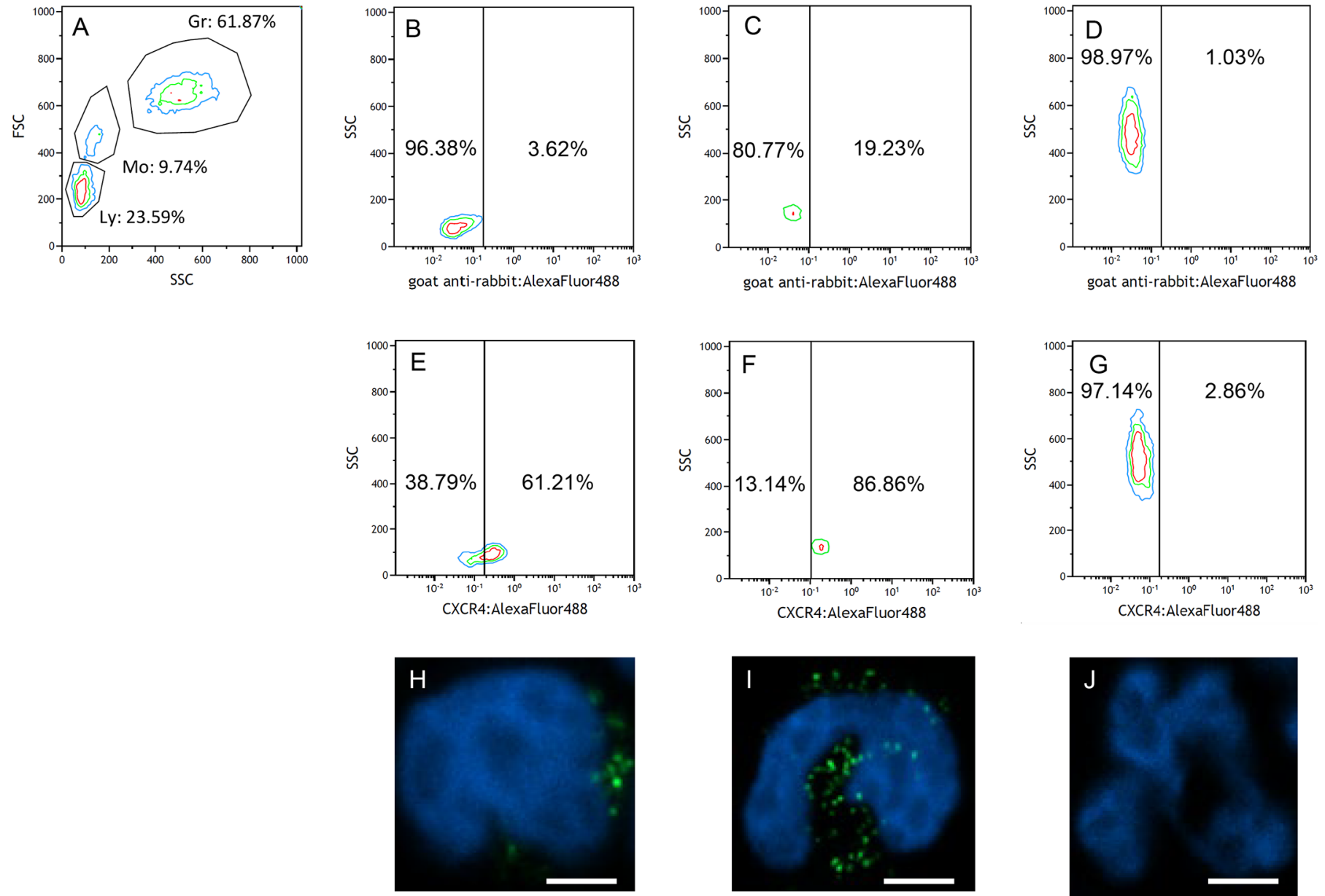

Figure 2. Flow cytometric analysis of CXCR4 distribution on bovine leukocytes. The data shown are the contour plot, forward scatter (FSC) $\times$ side scatter (SSC), of 10,000 counted cells (A). The gates Ly, Mo, and Gr represent lymphocytes, monocytes, and granulocytes, respectively. Fluorescence histograms (AlexaFluor 488 fluorescence intensity, $\log _{10}$ channel $\times$ SSC) show the portion of CXCR4-negative cells (B, Ly; C, Mo; and D, Gr). The portion of CXCR4-positive cells is demonstrated in panels E (Ly), F (Mo), and G (Gr), and the inserts of the immunofluorescence pattern of CXCR4 in lymphocytes $(\mathrm{H})$, monocytes $(\mathrm{I})$, and granulocytes $(\mathrm{J})$, where CXCR4 is represented in green and the nuclei in blue (Hoechst 33342). The scales indicate $5 \mu \mathrm{m}$. 
CXCR4 on lymphocytes and monocytes, with the highest expression per cell found on monocytes. In contrast, no surface expression was detectable on granulocytes. This finding was contrary to data in mice (Eash et al., 2009) or humans (Förster et al., 1998), where CXCR4 is expressed on neutrophils and plays an important role in the regulation of neutrophil homeostasis (Eash et al., 2009). Furthermore, the variability in CXCR4 expression on the surface of neutrophils in association with full reversible internalization was discussed as a mechanism of chemokine receptor regulation under inflammatory and noninflammatory conditions (Brühl et al., 2003).

To verify our results regarding neutrophils, we analyzed CXCR4 abundance in sorted leukocytes using Western blotting. We clearly detected the CXCR4 protein in all the analyzed cell types. These findings suggest intracellular storage of CXCR4 in bovine granulocytes, which is comparable to observations in human lymphocytes (Förster et al., 1998). In the latter, internal storage facilitates a rapid cellular response to stimuli via a fast transfer of internally stored CXCR4 to the cell surface (Förster et al., 1998).

Recently, a soluble form of the CXCR4 receptor was detected in humans, and an elevated concentration of CXCR4 in the serum of patients with inflammatory bowel disease was observed (Malvoisin et al., 2011). Soluble receptors are efficient anticytokine agents that are able to prevent excessive inflammatory responses by binding to chemokines (Malvoisin et al., 2011). It might be possible that bovine granulocytes also store CXCR4 receptors, which can be released to prevent an excessive inflammatory response. Further studies are necessary to detect a soluble form of the CXCR4 receptor in blood and determine its function in bovines.

We found that the PKC activator PMA had no effect on the surface abundance of CXCR4 on isolated bovine PBMC in our study. This observation was in contrast to studies in humans where PMA stimulation leads to rapid downregulation of CXCR4 from the surface of lymphocytes and neutrophils (Signoret et al., 1997; Förster et al., 1998; Brühl et al., 2003). We cannot exclude the possibility that the PBMC isolation process using Ficoll induces acute stress on these cells, which may affect the cell response to PMA. Further studies are necessary to identify differences in CXCR4 surface expression between isolated bovine PBMC and human cells of the immune system in response to PMA.

We demonstrated that supplementation with UFA but also coconut oil rich in lauric acid led to a reduction in CXCR4 expression on individual leukocytes. Using a Latin square design, we compared our data from the supplementation periods with the abundance of CXCR4 before starting the supplementation or at the end of each corresponding washout period, during which the cows were fed solely a corn-based TMR. The corn-based diet had a low n-3 FA content, leading to a high ratio of n-6 to n-3 FA (Haubold et al., 2020). Simopoulos (2008) showed that changes in the FA ratio toward higher n-6 FA levels increased the production of proinflammatory signals and therefore the response of the immune system. In the present study, all of the FA supplements led to reduced CXCR4 surface abundance on bovine total leukocytes, possibly leading to the reduction of specific proinflammatory signals in these cells. However, no effects were observed on the total number of CXCR4-expressing leukocytes or on the surface abundance of CXCR4 on isolated PBMC. Similarly, Haubold et al. (2020) did not observe any effect on the expression of inflammatory genes, such as $T N F$ or $H P$, in the liver using the same animal model. However, as shown by Brühl et al. (2003), the action of proinflammatory cytokines on the expression of CXCR4 seems to be cell type-specific.

A limitation of our study is the fact that we did not provide data on the mammary gland tissues or blood of dairy cows infected with mastitis-inducing pathogens

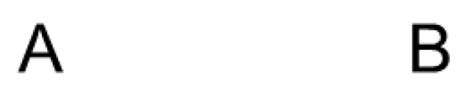

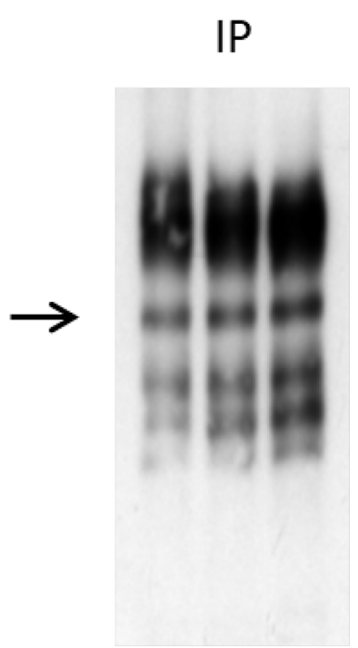

123
Flow-through

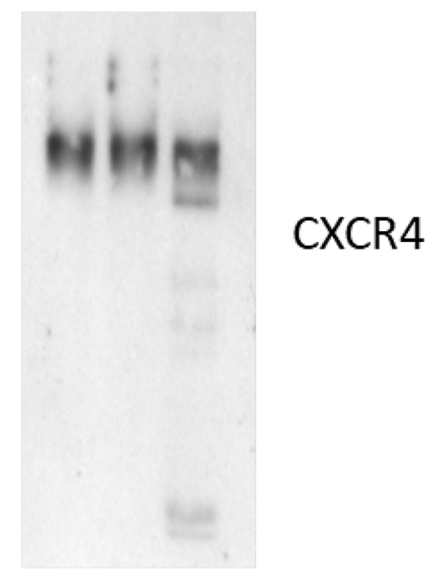

$\begin{array}{lll}1 & 2 & 3\end{array}$
Figure 3. The CXCR4 Western blotting analysis of gated bovine leukocytes after immunoprecipitation. Analyzed cells were lymphocytes (line 1), monocytes (line 2), and granulocytes (line 3). The cells were lysed and subjected to immunoprecipitation using an anti-CXCR4 Ab (Abcam, \#E18440). The immunoprecipitated fraction (IP) and flow-through fraction (flow-through) were analyzed by Western blotting $(\mathrm{n}=3)$. The CXCR4 signal is indicated by an arrow $(39 \mathrm{kDa})$. Strong signals in all lanes demonstrate IgG chains. 

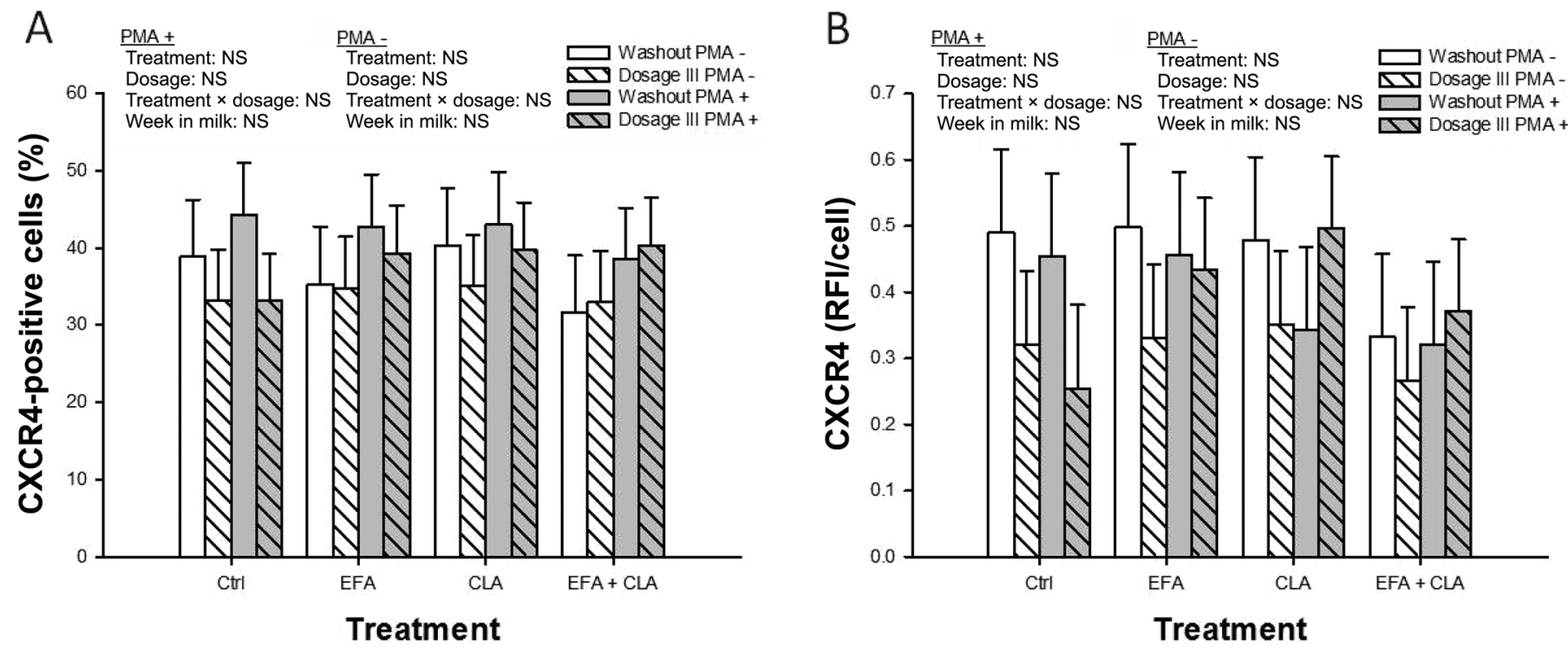

Figure 4. Flow cytometric quantification of CXCR4 surface expression on isolated bovine peripheral blood mononuclear cells and after stimulation with phorbol 12-myristate 13-acetate in vitro. The sampled dairy cows were fed a corn-based silage and supplemented with fatty acids for 6 wk with increasing dosages, followed by a 3-wk washout period in a Latin square design. The bar charts illustrate the portion of CXCR4-positive cells (A) and the relative amount of CXCR4 per cell (B). Ctrl = coconut oil; EFA = linseed and safflower oil mix; CLA = Lutalin (BASF); EFA + CLA = combination of EFA and CLA, PMA = phorbol 12-myristate 13-acetate, RFI = relative fluorescence intensity. The data are presented as LSM $\pm \mathrm{SE}(\mathrm{n}=4)$. No significant differences in CXCR4 surface expression could be determined after fatty acid supplementation or after PMA stimulation.

or across different lactational stages versus nonlactating dairy cows. Furthermore, methods should be established in the future to analyze the regulation of the surface expression of CXCR4 in different bovine tissues or cells as well as its potential secretion or shedding into the bloodstream.
A

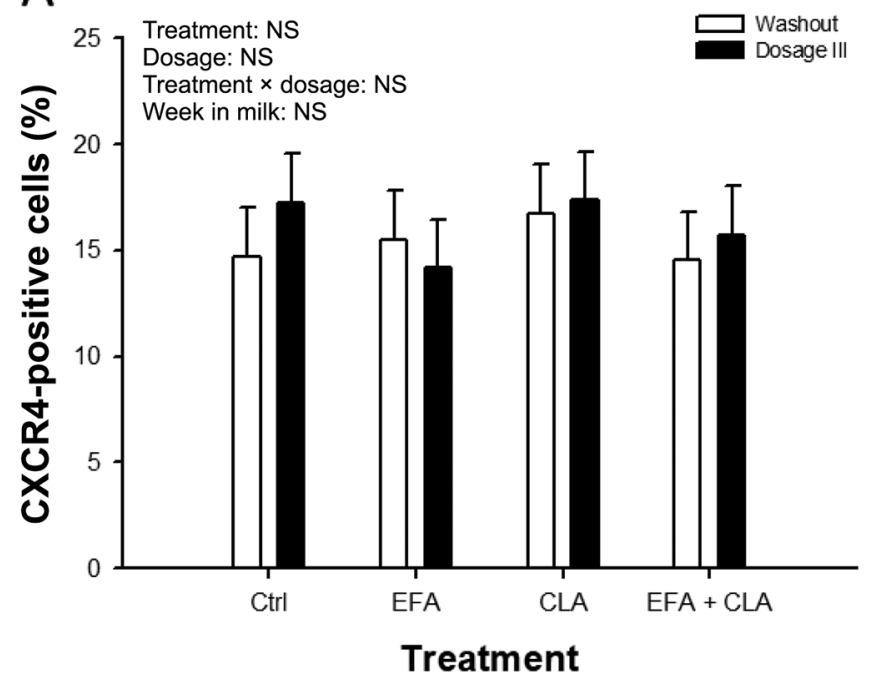

B

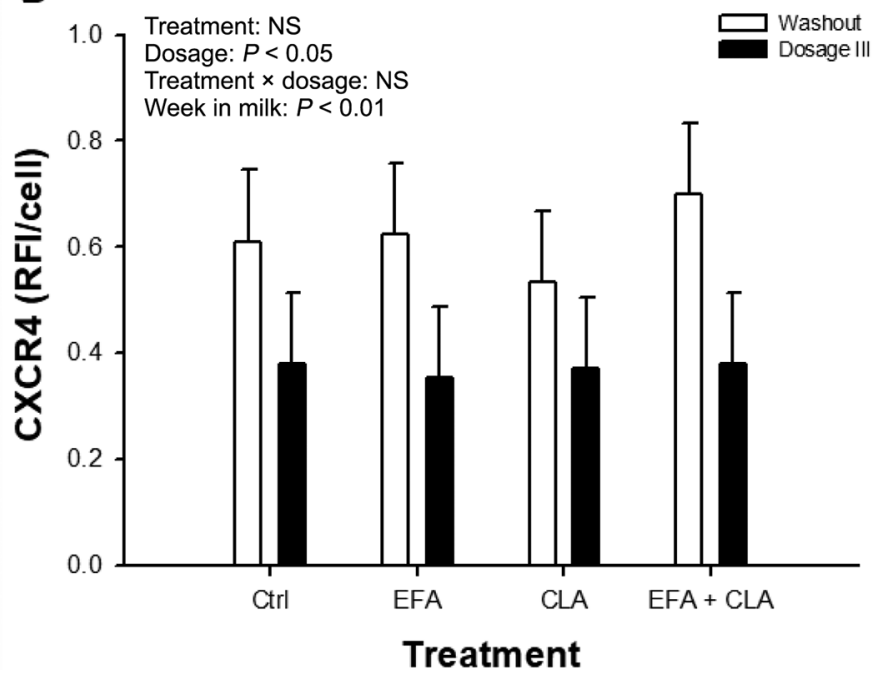

Figure 5. Flow cytometric quantification of CXCR4 surface expression on bovine leukocytes isolated from whole blood samples. The sampled dairy cows were fed a corn-based silage and were supplemented with fatty acids for 6 wk with increasing dosages, followed by a 3-wk washout period in a Latin square design. The bar charts illustrate the portion of cells (A) and the relative amount per cell (B) of all detected CXCR4positive cells $(10,000$ cells $)$. Ctrl = coconut oil; EFA = linseed and safflower oil mix; CLA = Lutalin (BASF); EFA + CLA = combination of FFA and CLA; Dosage III = highest dosage of the fatty acid supplement, RFI = relative fluorescence intensity. The data are presented as LSM $\pm \mathrm{SE}(\mathrm{n}=4)$. Significant differences were detected at the level of the individual cells. The relative abundance per cell decreased by fatty acid supplementation compared with the washout period (dosage, $P<0.05$ ). 


\section{CONCLUSIONS}

In the bovine mammary gland, epithelial cells of the LD but not AV show clear CXCR4 protein and mRNA signals. In bovine leukocytes, the highest signal intensity of CXCR4 was detected on the surface of monocytes, whereas granulocytes store CXCR4 intracellularly. In dairy cows fed a corn-based TMR, the surface expression of CXCR4 per leukocyte was reduced when these cows were abomasally supplemented with unsaturated FA or coconut oil. Therefore, all FA supplements can potentially affect the inflammatory status associated with the abundance of CXCR4 expression on individual leukocytes. The importance of our observations should be verified in cows infected with mastitis-inducing pathogens in the future.

\section{ACKNOWLEDGMENTS}

The authors thank A.-K. Möller (Institute of Nutritional Physiology, FBN, Dummerstorf, Germany) for excellent technical assistance. This work was supported by a grant from BASF Ludwigshafen, Germany. The publication of this article was funded by the Open Access Fund of the Research Institute for Farm Animal Biology (FBN). The authors have not stated any conflicts of interest.

\section{REFERENCES}

Aguinaga Casañas, M. A., C. T. Schäff, E. Albrecht, H. M. Hammon, B. Kuhla, M. Röntgen, G. Nürnberg, and M. Mielenz. 2017. Short communication: Free fatty acid receptors FFAR1 and FFAR2 during the peripartal period in liver of dairy cows grouped by their postpartum plasma beta-hydroxybutyrate concentrations. J. Dairy Sci. 100:3287-3292. https://doi.org/10.3168/jds.2016-11021.

Albrecht, E., T. Gotoh, F. Ebara, J. Wegner, and S. Maak. 2011. Technical note: Determination of cell-specific gene expression in bovine skeletal muscle tissue using laser microdissection and reversetranscription quantitative polymerase chain reaction. J. Anim. Sci. 89:4339-4343. https://doi.org/10.2527/jas.2011-4039.

Altenburg, J. D., and R. A. Siddiqui. 2009. Omega-3 polyunsaturated fatty acids down-modulate CXCR4 expression and function in MDA-MB-231 breast cancer cells. Mol. Cancer Res. 7:1013-1020. https://doi.org/10.1158/1541-7786.MCR-08-0385.

Bauman, D. E., L. H. Baumgard, B. A. Corl, and J. M. Griinari. 2000. Biosynthesis of conjugated linoleic acid in ruminants. J. Anim. Sci. 77(E-Suppl):1-15.

Bleul, C. C., L. Wu, J. A. Hoxie, T. A. Springer, and C. R. Mackay. 1997. The HIV coreceptors CXCR 4 and CCR 5 are differentially expressed and regulated on human T lymphocytes. Proc. Natl. Acad. Sci. USA 94:1925-1930. https://doi.org/10.1073/pnas.94.5 .1925 .

Brühl, H., C. D. Cohen, S. Linder, M. Kretzler, D. Schlöndorff, and M. Mack. 2003. Post-translational and cell type-specific regulation of CXCR4 expression by cytokines. Eur. J. Immunol. 33:3028-3037. https://doi.org/10.1002/eji.200324163.

Busillo, J. M., and J. L. Benovic. 2007. Regulation of CXCR4 signaling. Biochim. Biophys. Acta 1768:952-963.

Das, U. N. 2008. Essential fatty acids and their metabolites could function as endogenous HMG-CoA reductase and ACE enzyme inhibitors, anti-arrhythmic, anti-hypertensive, anti-atherosclerotic, anti-inflammatory, cytoprotective, and cardioprotective molecules. Lipids Health Dis. 7:37. https://doi.org/10.1186/1476-511X-7-37.

de Gaetano, M., E. Dempsey, S. Marcone, W. G. James, and O. Belton. 2013. Conjugated linoleic acid targets $\beta 2$ integrin expression to suppress monocyte adhesion. J. Immunol. 191:4326-4336. https: //doi.org/10.4049/jimmunol.1300990.

Döring, Y., L. Pawig, C. Weber, and H. Noels. 2014. The CXCL12/ CXCR4 chemokine ligand/receptor axis in cardiovascular disease. Front. Physiol. 5:212.

Eash, K. J., J. M. Means, D. W. White, and D. C. Link. 2009. CXCR4 is a key regulator of neutrophil release from the bone marrow under basal and stress granulopoiesis conditions. Blood 113:47114719. https://doi.org/10.1182/blood-2008-09-177287.

Edgar, R., M. Domrachev, and A. E. Lash. 2002. Gene Expression Omnibus: NCBI gene expression and hybridization array data repository. Nucleic Acids Res. 30:207-210. https://doi.org/10.1093/ nar/30.1.207.

Förster, R., E. Kremmer, A. Schubel, D. Breitfeld, A. Kleinschmidt, C. Nerl, G. Bernhardt, and M. Lipp. 1998. Intracellular and surface expression of the HIV-1 coreceptor CXCR4/fusin on various leukocyte subsets: Rapid internalization and recycling upon activation. J. Immunol. 160:1522-1531.

GfE (German Society of Nutrition Physiology). 2001. Recommended Energy and Nutrient Supply for Dairy Cows and Growing Cattle. DLG-Verlag.

GfE (German Society of Nutrition Physiology). 2008. New equations for predicting metabolisable energy of grass and maize products for ruminants. Mitteilung des Ausschusses für Bedarfsnormen der Gesellschaft für Ernährungsphysiologie. Proc. Soc. Nutr. Physiol. 17:191-198.

Harris, W. S. 2018. The Omega-6:Omega-3 ratio: A critical appraisal and possible successor. Prostaglandins Leukot. Essent. Fatty Acids 132:34-40. https://doi.org/10.1016/j.plefa.2018.03.003.

Hart, K. J., J. A. Huntington, R. G. Wilkinson, C. G. Bartram, and L. A. Sinclair. 2015. The influence of grass silage-to-maize silage ratio and concentrate composition on methane emissions, performance and milk composition of dairy cows. Animal 9:983-991. https:// doi.org/10.1017/S1751731115000208.

Haubold, S., C. Kröger-Koch, A. Starke, A. Tuchscherer, A. Tröscher, H. Kienberger, M. Rychlik, U. Bernabucci, E. Trevisi, and H. M. Hammon. 2020. Effects of abomasal infusion of essential fatty acids and conjugated linoleic acid on performance and fatty acid, antioxidative, and inflammatory status in dairy cows. J. Dairy Sci. 103:972-991. https://doi.org/10.3168/jds.2019-17135.

Jamali, H., H. W. Barkema, M. Jacques, E. M. Lavallée-Bourget, F. Malouin, V. Saini, H. Stryhn, and S. Dufour. 2018. Invited review: Incidence, risk factors, and effects of clinical mastitis recurrence in dairy cows. J. Dairy Sci. 101:4729-4746. https://doi.org/10.3168/ jds.2017-13730.

Khan, N. A., P. Yu, M. Ali, J. W. Cone, and W. H. Hendriks. 2015. Nutritive value of maize silage in relation to dairy cow performance and milk quality. J. Sci. Food Agric. 95:238-252. https:// doi.org/10.1002/jsfa.6703.

Malvoisin, E., J. M. Livrozet, D. Makloufi, and N. Vincent. 2011. Soluble chemokine receptor CXCR4 is present in human sera. Anal. Biochem. 414:202-207. https://doi.org/10.1016/j.ab.2011.03.022.

Maxymiv, N. G., M. Bharathan, and I. K. Mullarky. 2012. Bovine mammary dendritic cells: A heterogeneous population, distinct from macrophages and similar in phenotype to afferent lymph veiled cells. Comp. Immunol. Microbiol. Infect. Dis. 35:31-38. https://doi.org/10.1016/j.cimid.2011.09.009.

Mitterhuemer, S., W. Petzl, S. Krebs, D. Mehne, A. Klanner, E. Wolf, H. Zerbe, and H. Blum. 2010. Escherichia Coli infection induces distinct local and systemic transcriptome responses in the mammary gland. BMC Genomics 11:138. https://doi.org/10.1186/1471 -2164-11-138.

Nie, Y., J. Waite, F. Brewer, M. J. Sunshine, D. R. Littman, and Y. R. Zou. 2004. The role of CXCR4 in maintaining peripheral B cell compartments and humoral immunity. J. Exp. Med. 200:11451156. https://doi.org/10.1084/jem.20041185. 
Palmquist, D. L. 2010. Essential fatty acids in ruminant diets. Pages 127-141 in Proceedings of the 21th Annual Florida Ruminant Nutrition Symposium. Institute of Food and Agricultural Sciences, University of Florida.

Phipps, R. H., J. D. Sutton, and B. A. Jones. 1995. Forage mixtures for dairy cows: The effect on dry-matter intake and milk production of incorporating either fermented or urea-treated whole-crop wheat, brewers' grains, fodder beet or maize silage into diets based on grass silage. Anim. Sci. 61:491-496. https://doi.org/10.1017/ S1357729800014053.

Rego, O. A., P. V. Portugal, M. B. Sousa, H. J. D. Rosa, C. M. Vouzela, A. E. S. Borba, and R. J. B. Bessa. 2004. Effect of diet on the fatty acid pattern of milk from dairy cows. Anim. Res. 53:213-220. https://doi.org/10.1051/animres:2004010.

Revskij, D., S. Haubold, C. Plinski, T. Viergutz, A. Tuchscherer, C. Kröger-Koch, E. Albrecht, J. Günther, A. Tröscher, H. M. Hammon, H.-J. Schuberth, and M. Mielenz. 2021. Supplementary data to publication "Cellular detection of the chemokine receptor CXCR4 in bovine mammary glands and its distribution and regulation on bovine leukocytes" [Data set]. Zenodo. https://doi.org/ 10.5281/zenodo.5243358.

Revskij, D., S. Haubold, T. Viergutz, C. Kröger-Koch, A. Tuchscherer, H. Kienberger, M. Rychlik, A. Tröscher, H. M. Hammon, H. J. Schuberth, and M. Mielenz. 2019. Dietary fatty acids affect red blood cell membrane composition and red blood cell ATP release in dairy cows. Int. J. Mol. Sci. 20:2769. https://doi.org/10.3390/ ijms20112769.

Richter, C., T. Viergutz, M. Schwerin, and J. M. Weitzel. 2015. Prostaglandin E synthase interacts with inducible heat shock protein 70 after heat stress in bovine primary dermal fibroblast cells. Cytometry A 87:61-67. https://doi.org/10.1002/cyto.a.22595.

Salcedo, R., and J. J. Oppenheim. 2003. Role of chemokines in angiogenesis: CXCL12/SDF-1 and CXCR4 interaction, a key regulator of endothelial cell responses. Microcirculation 10:359-370. https:/ /doi.org/10.1080/mic.10.3-4.359.370.

Sayasith, K., and J. Sirois. 2014. Expression and regulation of stromal cell-derived factor-1 (SDF1) and chemokine CXC motif receptor 4 (CXCR4) in equine and bovine preovulatory follicles. Mol. Cell. Endocrinol. 391:10-21. https://doi.org/10.1016/j.mce.2014.04.009.

Shiah, Y. J., P. Tharmapalan, A. E. Casey, P. A. Joshi, T. D. McKee, H. W. Jackson, A. G. Beristain, M. A. Chan-Seng-Yue, G. D. Bader, J. P. Lydon, P. D. Waterhouse, P. C. Boutros, and R. Khokha. 2015. A progesterone-CXCR4 axis controls mammary progenitor cell fate in the adult gland. Stem Cell Reports 4:313-322. https:// doi.org/10.1016/j.stemcr.2015.01.011.

Signoret, N., J. Oldridge, A. Pelchen-Matthews, P. J. Klasse, T. Tran, L. F. Brass, M. M. Rosenkilde, T. W. Schwartz, W. Holmes, W. Dallas, M. A. Luther, T. N. Wells, J. A. Hoxie, and M. Marsh. 1997. Phorbol esters and SDF-1 induce rapid endocytosis and down modulation of the chemokine receptor CXCR4. J. Cell Biol. 139:651-664. https://doi.org/10.1083/jcb.139.3.651.

Simopoulos, A. P. 2008. The importance of the omega-6/omega-3 fatty acid ratio in cardiovascular disease and other chronic dis- eases. Exp. Biol. Med. (Maywood) 233:674-688. https://doi.org/ 10.3181/0711-MR-311.

Stoldt, A. K., M. Mielenz, G. Nürnberg, H. Sauerwein, T. Esatbeyoglu, A. E. Wagner, G. Rimbach, A. Starke, S. Wolffram, and C. C. Metges. 2016. Effects of a six-week intraduodenal supplementation with quercetin on liver lipid metabolism and oxidative stress in peripartal dairy cows. J. Anim. Sci. 94:1913-1923. https://doi .org/10.2527/jas.2016-0338.

Teicher, B. A., and S. P. Fricker. 2010. CXCL12 (SDF-1)/CXCR4 pathway in cancer. Clin. Cancer Res. 16:2927-2931. https://doi .org/10.1158/1078-0432.CCR-09-2329.

Triantafilou, K., M. Triantafilou, and R. L. Dedrick. 2001. A CD14-independent LPS receptor cluster. Nat. Immunol. 2:338-345. https: //doi.org/10.1038/86342.

Triantafilou, M., P. M. Lepper, C. D. Briault, M. A. Ahmed, J. M. Dmochowski, C. Schumann, and K. Triantafilou. 2008. Chemokine receptor 4 (CXCR4) is part of the lipopolysaccharide "sensing apparatus." Eur. J. Immunol. 38:192-203. https://doi.org/10.1002/ eji.200636821.

Viergutz, T., B. Loehrke, R. Poehland, F. Becker, and W. Kanitz. 2000. Relationship between different stages of the corpus luteum and the expression of the peroxisome proliferator-activated receptor gamma protein in bovine large lutein cells. J. Reprod. Fertil. 118:153-161. https://doi.org/10.1530/jrf.0.1180153.

Weiner, C. M., N. P. Smirnova, B. T. Webb, H. Van Campen, and T. R. Hansen. 2012. Interferon stimulated genes, CXCR4 and immune cell responses in peripheral blood mononuclear cells infected with bovine viral diarrhea virus. Res. Vet. Sci. 93:1081-1088. https:// doi.org/10.1016/j.rvsc.2012.01.011.

Widdison, S., N. Siddiqui, V. Easton, F. Lawrence, G. Ashley, D. Werling, M. Watson, and T. J. Coffey. 2010. The bovine chemokine receptors and their mRNA abundance in mononuclear phagocytes. BMC Genomics 11:439. https://doi.org/10.1186/1471-2164 $-11-439$.

Zárate, R., N. El Jaber-Vazdekis, N. Tejera, J. A. Pérez, and C. Rodríguez. 2017. Significance of long chain polyunsaturated fatty acids in human health. Clin. Transl. Med. 6:25. https://doi.org/10 .1186/s40169-017-0153-6.

\section{ORCIDS}

Denis Revskij ๑ https://orcid.org/0000-0002-6191-6093 Susanne Haubold ๑ https://orcid.org/0000-0002-5054-1978 Christian Plinski ๑ https://orcid.org/0000-0003-4005-1163 Elke Albrecht (๑) https://orcid.org/0000-0001-5974-1514

Juliane Günther ํㅏ https://orcid.org/0000-0002-6190-5044

Arnulf Tröscher (i) https://orcid.org/0000-0002-4198-4427

Harald M. Hammon @ https://orcid.org/0000-0001-8698-1257

Hans-Joachim Schuberth @ https://orcid.org/0000-0002-5904-5751

Manfred Mielenz @ ( https://orcid.org/0000-0002-5465-5817 